\title{
Multiple parallel skin markers for minimal incision lumbar disc surgery; a technical note Kai-Jow Tsai ${ }^{1}$, Shih-Hao Chen ${ }^{2}$ and Po-Quang Chen*3
}

Address: ${ }^{1}$ Department of Orthopedic Surgery, Cathay General Hospital, Taipei, Taiwan, ${ }^{2}$ Department of Orthopedic Surgery, Chang-Gung Memorial hospital, Taipei, Taiwan and ${ }^{3}$ Department of Orthopedic Surgery, National Taiwan University Hospital, Taipei, Taiwan

Email: Kai-Jow Tsai - tsaikj@ms2.hinet.net; Shih-Hao Chen - shihhao@adm.cgmh.org.tw; Po-Quang Chen* - pqchen@ccms.ntu.edu.tw

* Corresponding author

Published: 16 March 2004

BMC Musculoskeletal Disorders 2004, 5:8

This article is available from: http://www.biomedcentral.com/I47I-2474/5/8

(C) 2004 Tsai et al; licensee BioMed Central Ltd. This is an Open Access article: verbatim copying and redistribution of this article are permitted in all media for any purpose, provided this notice is preserved along with the article's original URL.
Received: 15 July 2003

Accepted: 16 March 2004

\begin{abstract}
Background: Spinal surgery depends on accurate localization to prevent incorrect surgical approaches. The trend towards minimally invasive surgery that minimizes surgical exposure and reduces postoperative pain increasingly requires surgeons to accurately determine the operative level before an incision is made. Preoperative localization with a $\mathrm{C}$-arm image intensifier is popular, but the exposure of both patients and theatre staff to radiation is a disadvantage, as well as being time-consuming.
\end{abstract}

Methods: We describe a simple surgical tool developed to help localize exact spinal levels in conjunction with a simple AP X-ray film immediately before surgery. Multiple parallel skin markers were made using a circular oven rack comprising multiple $1.5 \mathrm{~cm}$ spaced parallel wires attached to a circular outside rim. The longest line was placed on the line of the postero-superior iliac spine (PSIS) over the junction of the L5-SI region.

Results and conclusions: Based on the film taken, the incision can be accurately made at the intended level. The incision wound can be minimized to $3.0 \mathrm{~cm}$ even when using conventional disc surgery instruments.

\section{Background}

Lumbar disc surgery is one of the most common procedures in spinal surgery that was discovered by Mixter and Barr in 1934 [1], and selecting the correct level for the skin incision is critical. The conventional method of localizing the correct level is palpation of the spinous processes of the lumbar spine and iliac crests $[2,3]$. This technique is difficult in obese patients who may require a longer skin incision so that the fascia and muscle layers can be opened. The surgeon can then confirm the exact level for the discectomy by palpation and movement of the fifth lumbar vertebra rather than the motionless sacrum. A clip is sometimes necessary to identify the correct level after radiographic confirmation during anesthesia. The con- ventional approach usually requires a wound 5 to 10 centimeters in length. An intraoperative lateral view of the lumbar spine is then made by permanent film or fluoroscopically to confirm the level of the intended discectomy, adding to the radiation exposure of both theatre staff and the patient.

In this article, a new technique is described that can help to minimize the skin incision required by more simply and effectively identifying the correct spinal level.

\section{Methods}

Under general anesthesia, the patient is evenly placed in a prone position on the frame, suspending the abdomen to 


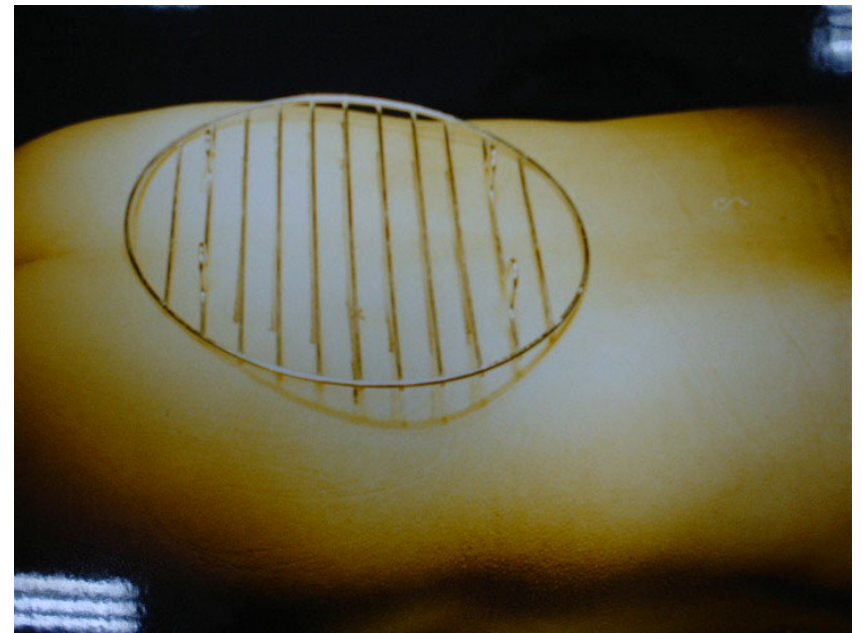

Figure I

A circular oven rack is placed over the surgical field.

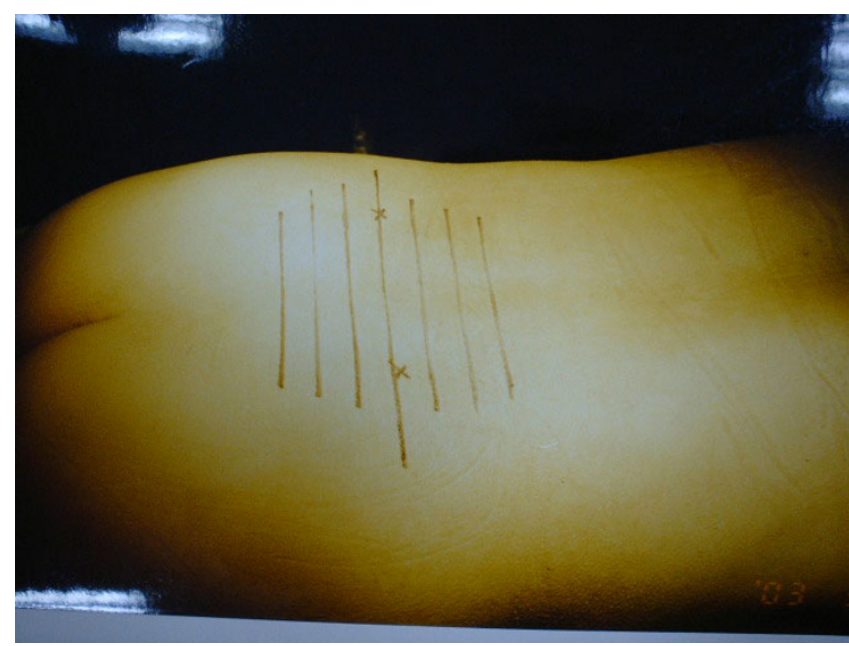

Figure 2

Multiple parallel lines are drawn on the skin along the parallel wires of the oven rack with a permanent marker pencil.

relieve abdominal pressure. The posterior superior iliac spines (PSIS) are palpated and lines drawn to connect both PSIS's with a permanent marker pencil. This line is supposed to pass between L5 and S1. A circular oven rack is then placed on the surgical field (Fig. 1). A preoperative permanent posterior-anterior (PA) film is then taken. Multiple parallel lines are then drawn on the skin along the $1.5 \mathrm{~cm}$ spaced parallel wires of the oven rack with the permanent marker pencil (Fig. 2). The surgical field is then disinfected and draped. The PA film of the lumbar

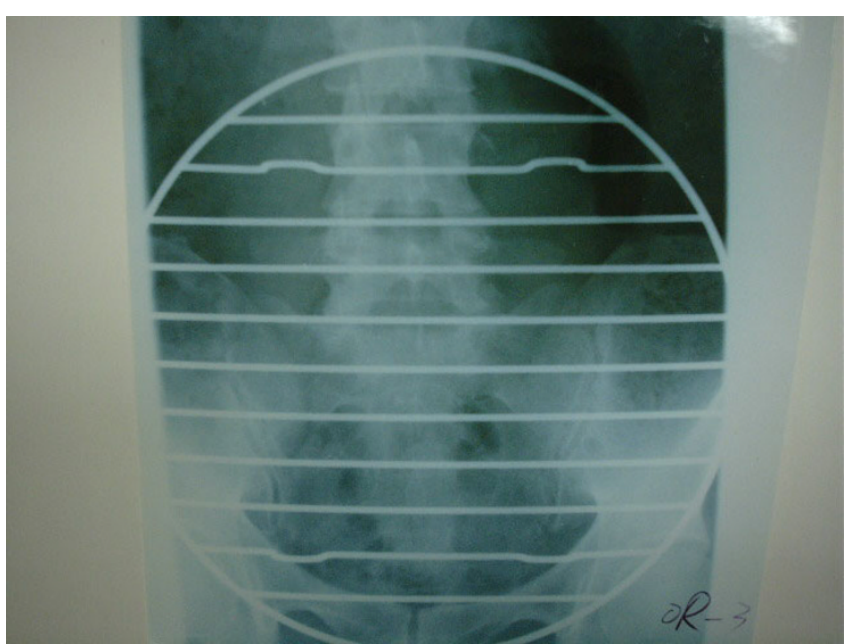

Figure 3

The PA lumbar film shows the correct lumbar spine level.

spine allows the correct level of the lumbar spine to be determined simply by counting the lines until the desired disc space is reached (Fig. 3). A small incision is then made.

\section{Results}

Usually, a $3 \mathrm{~cm}$ incision is needed for one-level disectomy (Fig. 4). The fascia is incised at the midline using electrocautery, and a periosteal elevator is inserted in the midline incision. Using gentle lateral movements, the deep fascia and muscle is subperiosteally separated from the spinous processes and lamina. Meticulous electrocautery is needed to minimize bleeding. A finger is then inserted to allow palpation of the interlaminar space. If necessary, bayonet forceps are placed in the interlaminar space and a permanent lateral view is again taken to confirm the level before performing the discectomy.

\section{Discussion}

Conventional lumbar disc surgery as described in textbooks employs a midline incision 5 to $10 \mathrm{~cm}$ in length from the spinous process of L4 to S1 [2]. The level of the iliac crest revelaed by the plain film of lumbar spine was used to determine the spinous process of $\mathrm{L} 4$ [3]. The surgeon exposes the interspaces under direct vision so that no mistake is made while exploring the interspaces. The fascia, tendon and muscles are sacrificed in these procedures. The disc surgery itself involves decompression of the nerve root to relieve pain. If too much soft tissue and bone is damaged, post-operative pain is inevitable. Lumbodorsal fascia injury also leads to postoperative pain and can limit the back's range of motion postoperatively. 


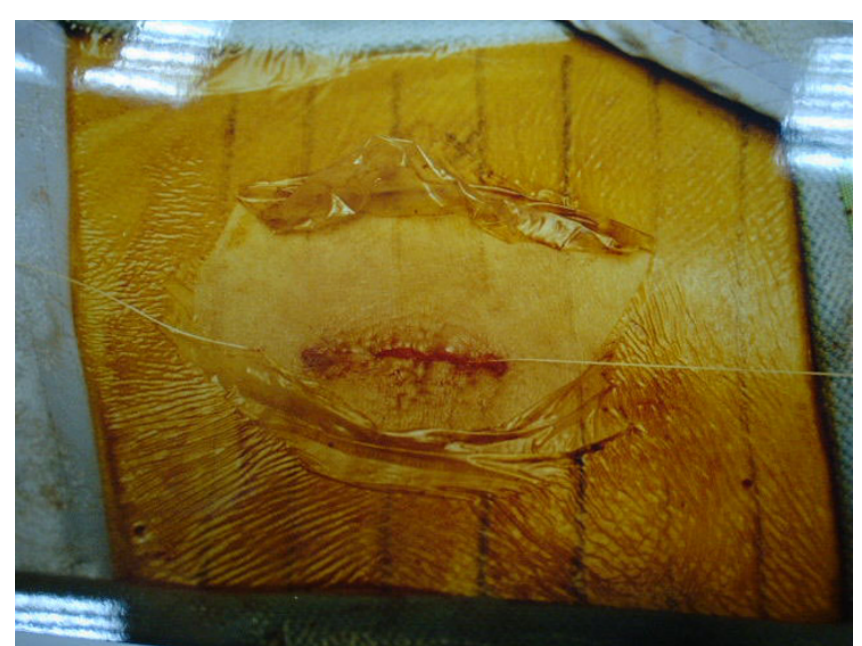

Figure 4

A $3 \mathrm{~cm}$ incision is needed for one-level discectomy.

The micro lumbar disectomy was developed in order to minimize injury to the musculature of the back. An operative microscope is used for better visualization and special retractors and miniature instruments are used for the discectomy itself [4]. Curettage of the disc space is not mandatory. The use of the microscope can lead to loss of three-dimensional visualization and introduces another potential source of operative field contamination. The preoperative localization of the surgical level is made with spinal needles $[5,6]$. Two \#20 gauze spinal needles are inserted perpendicularly to the skin approximately threefinger widths lateral to the spine, and lateral skin marker radiographs are then obtained. The skin incision is then made midline over the disc space. The paraspinous needles allow more accurate skin incision placement than a spinous process marker. The disadvantages are that spinal needle insertion may increase the risk of infection, and that it is a time-consuming procedure.

The arthroscopic micro discectomy was introduced by Kambin and colleagues $[7,8]$. An $8 \mathrm{~mm}$ internal diameter cannula is introduced into the triangular working zone. Intraoperative fluoroscopic images are used to navigate the position of an oval cannula in these zones between the traversing and exiting nerve roots at the dorso-lateral aspect of the intervertebral disc. The percutaneous nuclectomy was described by Hijikata. In the procedures, the fluoroscopic image control is indispensable to confirm and document disc penetration and to watch the annulus cutter does not go too far to the other margin $[9,10]$. The continuous exposure of theatre staff and the patient to $\mathrm{x}$ ray radiation is the chief concern with this technique.
The miminal acess surgery for the anterior lumbar spine fusion described by Huang and colleagues [11]. The techniques to localize the exact disc level was approached with the aid of C-arm intensified in an anteroposterior (AP) direction. Then an intersection point formed by the kirschner wire and the extension line of the anterior axillary line of the patient was marked. With this method, the need for radiologic check in a lateral direction was circumvented. The confirmation was obtained by a C-arm intensifier during the operation. Miccoli and colleagues developed minimally invasive video-assisted approach to the cervical spine. They inserted a $1-\mathrm{mm}$ metal probe to exactly localize during fluoroscopy the vertebrae reached by the dissection for the anatomic-ragiologic study [12]. In these procedures, the preoperative localization was performed by fluoroscopy and the exposure to radiation of surgeons and patients is inevitable.

The currently described procedure produces multiple parallel skin markers that correspond to the PA view of the patient positioned on the operating table. The patient needs to be placed evenly on the table to prevent differences arising with movement between the skin markers and interspaces of the lumbar spine. The intraoperative lateral radiograph is essential for confirmation of the level before laminectomy.

\section{Conclusions}

The presently described technique has the advantages of simplicity, being non-invasive to the surgical field, low cost and a straightforward posterior approach to the spine which does not need to depend on spinous process palpation or additional lateral radiographs. The PA radiograph with parallel wires enables the correct level of the lumbar spine to be counted from the film and skin markers and the incision to be centered to the disc space using just the PA radiograph, helping to minimize the size of the required incision and exposure to radiation. One final benefit of the technique is that it can also be used as an aid for endoscopic or micro-discectomy surgery.

\section{Abbreviations}

PSIS: posterior superior iliac spine

PA: posteroanterior

\section{Competing interests}

None declared.

\section{Authors' contributions}

KJT: original idea of this paper and paper writing

SHC: paper writing advice.

PQC: paper writing revision, supervisor. 


\section{References}

I. Mixter WJ, Barr JS: Rupture off the intervetebral disc with involvement of the spinal canal. N Engl J Med 1934, 21 I:2 I 0-2 I 5.

2. Wood GWI: Lower back pain and disorders of intervertebral disc. In: Campbell's Operative Orthopaedics Ninthth edition. Edited by: Canale ST. St. louis: MY press; 1998:3058-3065.

3. Simeon FA: The neurosurgical approach to lumbar disc disease. Orthopedic Clinics of North America I97I, 2:499.

4. Williams RW: Microlumbar discectomy: a conservative surgical approach to the virgin herniated lumbar disc. Spine 1978, 3(2): $175-182$.

5. Watkins RG: Surgical approaches to the spine. In: Chapman's Orthopedic Surgery Thirdth edition. Edited by: Chapman MW. Philadelphia: LWW; 200I:3654-3655.

6. Wilson D, Harbaugh R: Microsurgical and standard removal of the protruded lumbar disc: a comparative study. Neurosurgery I 98I, 8:422-427.

7. Hermantin FU, Peters T, Quartararo L, Kambin P: A prospective, randomized study comparing the results of open discectomy with those of video-assisted arthroscopic microdiscectomy.J Bone Joint Surg Am 1999, 8 I (7):958-965.

8. Kambin PGH: Percutaneous lateral discectomy of the lumbar spine, A preliminary report. Clin Orthop 1983, 174:127-132.

9. Hijikata S: Percutaneous nucleotomy: a new concept of technique and I 2 years' experience. Clin Orthop 1989, 238:9.

10. Hijikata S, Yamagish M, Nakayama T, Oomori K: Percutaneous nuclectomy. A new treatment method for lumbar disc herniation. J Toden Hosp 1975, 5:39.

II. Huang TJ, Hsu RWW, Chen SH: Minimal access surgery in managing anterior lumbar disorders. Clin Orthop 200I, 387: I 40-I 47.

12. Miccoli P, Berti P, Raffaelli M, Materazzi G, Conte M, Faldini A: Minimally invasive approach to the cervical spine: $A$ proposal. Journal of Laparoendoscopic \& Advanced Surgical Techniques 200I, I I(2):89-92.

\section{Pre-publication history}

The pre-publication history for this paper can be accessed here:

http://www.biomedcentral.com/1471-2474/5/8/prepub

Publish with Bio Med Central and every scientist can read your work free of charge

"BioMed Central will be the most significant development for disseminating the results of biomedical research in our lifetime. "

Sir Paul Nurse, Cancer Research UK

Your research papers will be:

- available free of charge to the entire biomedical community

- peer reviewed and published immediately upon acceptance

- cited in PubMed and archived on PubMed Central

- yours - you keep the copyright

Submit your manuscript here:

http://www.biomedcentral.com/info/publishing_adv.asp
BiolMedcentral 